\title{
Optimal allocation model of plant community in slope ecological restoration
}

\author{
Wang Q. ${ }^{1,2}$, Li M. ${ }^{1,2}$ and Xie X.1,2* \\ ${ }^{1}$ School of Architecture and Urban Planning, Shenzhen University, Shenzhen 518060, China \\ ${ }^{2}$ Shenzhen Key Laboratory of Built Environment Optimization, Shenzhen University, Shenzhen 518060, China \\ Received: 02/07/2020, Accepted: 06/08/2020, Available online: 22/10/2020 \\ *to whom all correspondence should be addressed: e-mail: Horticulturist1@163.com \\ https://doi.org/10.30955/gnj.003388
}

\section{Graphical abstract}

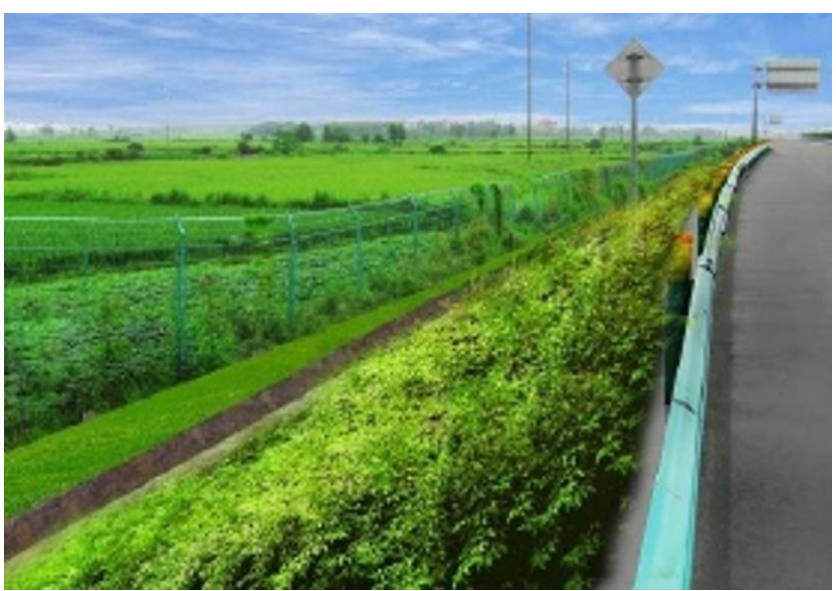

\section{Abstract}

In order to effectively analyze the optimal allocation mode of plant community in the process of slope ecological restoration, 15 plants were selected and 10 plant community combinations were designed. The experiment lasted for 90 days, and the optimal allocation model of plant community was obtained. The optimal allocation pattern of plant communities in slope ecological restoration was C7: 10 plants of Amorpha fruticosa+20 plants of Vitex negundo+30 plants of Festuca arundinacea+20 plants of Moxa argyi+10 plants of Dianthus caryophylla+20 plants of Lespedeza+10 plants of Leucaena+8 plants of Acacia; C8: 30 plants of Euonymus microphylla +10 plants of Shearnut +20 plants of Alfalfa +30 plants of Pigeon Beans+20 plants of Crotalaria mucronata+20 plants of Mimosa bimucronata; C3: 20 plants of Amorpha fruticosa+50 plants of Euonymus fortunei var. radicans +20 plants of Aicao +10 plants of Pigeon bean +8 plants of Leucaena +10 plants of Dodonaea viscosa. The experimental results show that the optimal allocation model of plant community is effective in slope ecological restoration.

Keywords: Slope, ecological restoration, plant community, optimization, allocation, model.

\section{Introduction}

Slope refers to the slope with a certain gradient made on both sides of the roadbed in order to ensure the stability of the roadbed. Slope ecological restoration is a new technology of slope protection developed in recent years (Guo and Huang, 2017). At present, there are many ecological restoration methods for different slopes, such as hydraulic spraying, vegetation concrete slope protection greening, three-dimensional vegetation net spraying grass planting, thick base material spraying vegetation slope protection, slope TBS vegetation slope protection greening and so on (Vimalraj et al., 2019; Xuan and Gao, 2017). In the early stage of ecological restoration, plants grow vigorously and soil and water conservation effect is good. However, with the passage of time, plants will decline and it is difficult to form stable plant communities (Liu et al., 2017). The reasons are as follows: firstly, herbaceous plants are mostly used in the process of ecological restoration, while shrubs and vines are seldom used, and plant communities lack diversity (Aja et al., 2020; Peng et al., 2017); secondly, the adaptability and sustainability of habitat base materials are insufficient.

Any stable plant community is composed of a variety of plant species. Because each plant has its own requirements and responses to the environment, it plays a different role in the community (Liu et al., 2018). How to use vegetation restoration to reconstruct the damaged high and steep rocky slope, how to change the characteristics of the artificial vegetation community in the natural succession process and whether the artificial vegetation community can reach the stable state of natural vegetation have become an important topic in recent years (Wang et al., 2018a). The ultimate goal of slope ecological restoration is to establish a stable and healthy plant community and restore its original ecological function. Therefore, the types of community succession in the future should be considered, and the target plant community should be designed reasonably according to different ecological restoration methods and the succession law of plant community (Xue et al., 2017), (Emanuel and Uffe, 2020). 
However, herbaceous plants are still the main constructive species in slope ecological restoration. The types of communities formed are relatively single and the stability of communities is poor.

The ecological restoration and reconstruction of highway slope has become one of the hotspots of restoration ecology. According to statistics, for every $1 \mathrm{~km}$ highway construction in our country, the area of bare slope is about $50-70,000 \mathrm{~m}^{2}$, and the area of slope formed by highway construction in our country is about 200-300 million $\mathrm{m}^{2}$ every year. As a result, the area of high and steep bare rock slope is also increasing (Poudel et al., 2019; Wood et al., 2017). At present, one of the key technologies for artificial ecological restoration of such damaged slopes in China and abroad (such as hydraulic spraying, vegetation concrete slope protection greening, three-dimensional vegetation net spraying grass planting, thick base material spraying vegetation slope protection, slope TBS vegetation slope protection greening, etc.) is the rationality of artificial spraying medium and vegetation community restoration. However, the main problems in recent years are that the natural maintenance time of landscape effect is too short after the completion of the project, and there are many problems after the implementation of the project, such as not obvious improvement of elevation habitat, simple community structure, rapid plant death and high cost (Muller et al., 2017; Pipas and Varun et al., 2019). Generally, in the early stage of ecological restoration, plant growth is vigorous and soil and water conservation is good. However, with the passage of time, the plant community will decline, the revegetation tends to be single, and it is difficult to form a stable plant community (Rapai et al., 2018). One of the main reasons is that the reasonable combination of grass, shrub and arbor is less considered, either focusing on short-term restoration effect, or stressing construction cost, or even the phenomenon of direct planting of single shrub or single herb. The vegetation is all Bahia grass, and the plant community lacks diversity (Niu et al., 2017; Olusola, 2020).

At present, there are many studies on plant community allocation of slope in China. Li Ziqiang et al. through plant planting experiments, according to the adaptability of different plants, slope coverage, growth years and other factors, using analytic hierarchy process, according to the site conditions of the northern section of Shizhong Expressway, selected the slope with strong stress resistance and good slope protection effect. Slope greening plants with low cost and long-lasting protection effect; Zhang Rui took the ecological restoration of slope as the research object, proposed that herbs, shrubs and vines are high-quality plant species on the slope of expressway, expounded the selection principle of high-quality plants, and provided an effective basis for the selection of slope protection plants of Expressway (Tian et al., 2017). He Huanyu takes the Loess Gully ecological region of Henan Province as the research object. On the basis of understanding the ecological restoration and landscape status of the slope in the region, he expounds the geological conditions and production forms of different slope protection forms. Combining with the analysis of hydro-climatic conditions and highway public land conditions in the Loess Gully ecological region, he puts forward that the slope is fragile (Qolipour et al., 2019; Ullah et al., 2019). Landscape ecological design model of soil improvement and vegetation restoration in ecological environment has created plant communities on slopes with stable structure, high biodiversity and seasonal variation. In this study, the initial rational combination of plant communities across Xinnan high-speed slope in Nanyang City, Henan Province was optimized. From the perspective of constructing reasonable early spraying plant combination, the long-term effectiveness of plant communities was prolonged, which provided a theoretical basis and practical reference for the eventual formation of stable communities for ecological restoration of slope.

\section{Materials and methods}

\subsection{Survey of research areas}

Xinnan Expressway passes through Nanyang City, Henan Province, which belongs to the transition zone from subtropical monsoon climate to warm temperate continental climate. It has the most abundant water and heat resources. The high-water period (from July to September) and the low-water period (from December to March) are obvious, and the four seasons are distinct. Winter is dry and cold with little rain and snow; summer is hot with plenty of rain. The annual average temperature is $14.4-15.7^{\circ} \mathrm{C}$, the hottest monthly average temperature is 26.9-28. $0^{\circ} \mathrm{C}$, and the coldest monthly average temperature is $0.5-2.4^{\circ} \mathrm{C}$ (Rahman et al., 2018). The average annual rainfall is $703.6-1173.4 \mathrm{~mm}$, mainly concentrated in JuneSeptember, accounting for $60-68 \%$ of the total annual rainfall. There is a great difference in rainfall along the line from east to West (Yoshitaka et al., 2018). The annual sunshine time was 1897.9-2120.9 hours and the annual frost-free period was 220-245 days. The main native arbor species are Amorpha fruticosa, Euonymus fortune var. radicans, Alfalfa, tall fescue, mugwort and so on.

\subsection{Research method}

Plant survey: A, B, C and D plots were observed regularly for 90 days from July 2018 to September 2018 by field investigation and inductive summary. 10 plots of $100 \mathrm{~cm}$ in length and $50 \mathrm{~cm}$ in width were randomly set up in four plots (Wang et al., 2018b). At the same time, the method of trampling was used to sample and investigate the section along the expressway. The number of piles in the section was K1071, K1081, K1121-1123, K1121-1122, K1273, K1265-1266, K1264-1265, K1248, K1024-1023 and K1354-K1355. Through field investigation, the species, characteristics, community structure, plant growth and landscape effects of the plants in the road area were recorded. Photographs, specimen collection, complete records of their habitats and detailed identification of unknown vegetation were also taken (Shen et al., 2019). It also summed up the local plants suitable for Expressway Greening in this section, and based on the principle of restoration ecology design its application method (Liang et al., 2017). Vegetation coverage (needling method), aboveground and underground biomass refer to the "Experimental Manual of Plant Communities". Data of 
aboveground and underground biomass, root diameter and tensile strength of vegetation are analyzed and summarized according to the data of vegetation flourishing period (August).
The specific information of sampling site of fixed-point slope experimental section is shown in Table 1.

Table 1. Specific information of the fixed-point experimental slope section

\begin{tabular}{ccccc}
\hline Sampling point & Slope type & Position & Station number & Slope \\
\hline Section A & Sand filled embankment & Luohe Town, Wancheng District, Nanyang & K1121 & \\
& & City & K1:01.5 \\
\hline Section B & Sub-clay roller slope & Chenzhuang, Biyang County & K1035 & $01: 01.8$ \\
\hline Section C & Fully weathered rock & Nangang, Huanggang, Township & K1036 & $01: 01.5$ \\
\hline Section D & Weathered rock road slope & Nangang, Huanggang, Township & K1010 & $01: 01.5$ \\
\hline
\end{tabular}

Table 2. Experimental material

\begin{tabular}{|c|c|c|c|c|c|c|c|}
\hline \multicolumn{2}{|c|}{ Serial number } & \multicolumn{2}{|c|}{ Genus } & \multicolumn{2}{|l|}{ Branch } & \multicolumn{2}{|c|}{ Sort } \\
\hline \multicolumn{2}{|c|}{1} & \multicolumn{2}{|c|}{ Amorpha } & \multicolumn{2}{|l|}{ Legume } & \multicolumn{2}{|c|}{ Amorpha } \\
\hline \multicolumn{2}{|r|}{2} & \multicolumn{2}{|c|}{ Vitex } & \multicolumn{2}{|l|}{ Verbenaceae } & \multicolumn{2}{|c|}{ Vitex L. } \\
\hline \multicolumn{2}{|r|}{3} & \multicolumn{2}{|c|}{ Euonymus sinensis } & \multicolumn{2}{|l|}{ Euonymus } & \multicolumn{2}{|c|}{ Euonymus } \\
\hline \multicolumn{2}{|r|}{4} & \multicolumn{2}{|c|}{ Tall fescue } & \multicolumn{2}{|l|}{ Euonymus } & \multicolumn{2}{|c|}{ Euonymus } \\
\hline \multicolumn{2}{|r|}{5} & \multicolumn{2}{|c|}{ Snakeberry } & \multicolumn{2}{|l|}{ Rosaceae } & \multicolumn{2}{|c|}{ Snakeberry } \\
\hline \multicolumn{2}{|r|}{6} & \multicolumn{2}{|c|}{ Wormwood } & \multicolumn{2}{|l|}{ Compositae } & \multicolumn{2}{|c|}{ Artemisia } \\
\hline \multicolumn{2}{|r|}{7} & Alfo & & Legume & & GeI & \\
\hline & 8 & Dian & & Dianthus & & Dian & \\
\hline & 9 & Cajanu & & Legume & & GeI & \\
\hline & 10 & Lespedez & icolor & Legume & & GeI & \\
\hline & 11 & Crotalari & allida & Legume & & Sw & \\
\hline & 12 & Leucaen & auca & Legume & & Aca & \\
\hline & 13 & Mimosa & iaria & Legume & & Mim & \\
\hline & 14 & Dodonae & scosa & Sclerotia & & Ger & \\
\hline & 15 & Acacia fa & siana & Legume & & Aca & \\
\hline $\begin{array}{c}\text { Serial } \\
\text { number }\end{array}$ & Plant name & pull/N & diameter/mm & $\begin{array}{c}\text { Root to } \\
\text { crown ratio }\end{array}$ & $\begin{array}{c}\text { Important } \\
\text { value }\end{array}$ & $\begin{array}{c}\text { Growth } \\
\text { potential }\end{array}$ & $\begin{array}{c}\text { Landscape } \\
\text { effect }\end{array}$ \\
\hline 1 & Amorpha & 480.00 & 8.50 & 1.52 & 0.75 & Excellent & Excellent \\
\hline 2 & Vitex & 350.00 & 4.50 & 1.25 & 0.67 & Excellent & Excellent \\
\hline 3 & Euonymus sinensis & 20.00 & 0.20 & 2.51 & 0.8 & Good & Medium \\
\hline 4 & Tall fescue & 18.80 & 0.53 & 1.17 & 0.28 & Excellent & Excellent \\
\hline 5 & Snakeberry & 9.89 & 0.92 & 2.14 & 0.32 & Excellent & Good \\
\hline 6 & Wormwood & 30.72 & 1.49 & 1.33 & 0.19 & Good & Excellent \\
\hline 7 & Alfalfa & 290.00 & 2.50 & 0.46 & 0.72 & Excellent & Good \\
\hline 8 & Dianthus & 35.00 & 1.80 & 2.35 & 0.26 & Good & Excellent \\
\hline 9 & Cajanuscajan & 47.58 & 2.73 & 1.26 & 0.33 & Excellent & Good \\
\hline 10 & Lespedeza bicolor & 20.00 & 4.13 & 1.74 & 0.18 & Good & Excellent \\
\hline 11 & Crotalaria pallida & 35.14 & 5.08 & 1.69 & 0.25 & Excellent & Medium \\
\hline 12 & Leucaena glauca & 151.23 & 6.14 & 2.05 & 0.63 & Excellent & Good \\
\hline 13 & Mimosa sepiaria & 208.65 & 8.05 & 1.48 & 0.48 & Excellent & Excellent \\
\hline 14 & Dodonaea viscosa & 28.00 & 0.42 & 1.32 & 0.13 & Medium & Good \\
\hline 15 & Acacia farnesiana & 29.84 & 1.33 & 1.04 & 0.86 & Excellent & Good \\
\hline
\end{tabular}

\subsection{Plant community in slope ecological restoration}

Through investigation and summary, 52 kinds of native plants for slope greening (excluding shoulder) were investigated, mainly Leguminous, Gramineae and Compositae (Haapalehto et al., 2017). 6 species of Leguminous, mainly includes Alfalfa, Amorpha fruticosa, and white clover; 11 species of Gramineae, mainly includes ryegrass, tall fescue, oat, etc.; 8 species of Compositae, mainly includes Artemisia argyi, Artemisia annua and Xanthium sibiricumetc. Uncommon vegetations include madder, bursa pastoris, Heteropappushispidus, geranium,
Euphorbia, barnyard grass, etc. Fifteen common slope greening plants, such as Amorpha fruticosa, Vitex negundo, Euonymus fortune var. Radicans, tall fescue, snakeberry, moxa grass, Alfalfa and carnation, were taken as examples to analyze and summarize the height, aboveground and underground biomass, tensile strength and root diameter of vegetation (Lindh, 2018) in order to match plant communities. The optimization of the location model provides the basic data base. The specific names of 15 kinds of slope greening plants and their subordinate subjects are shown in Table 2. 
The specific information of tensile strength and root diameter of 15 kinds of slope greening plants are shown in Table 3. The measurement methods of root tensile strength are as follows: root tensile strength is measured by spring scale tensiometer ( $50 \mathrm{~N}$ and $500 \mathrm{~N}$ ), and diameter is measured by vernier caliper (Wei et al., 2017). Excel is used for data statistics and data analysis.

Considering that the thickness of the spraying matrix used for ecological restoration of high and steep rock slopes is generally only $8-10 \mathrm{~cm}$, and the conditions of nutrition and water are very limited (Wu et al., 2018), this study takes into account the characteristics of plant root distribution, interspecific competition, soil and water conservation effect, drought tolerance and barrenness tolerance. Fifteen kinds of high and steep slopes in Henan Province are selected from the above. There are 10 combinations of grass, shrub and arbor vegetation types commonly used in ecological restoration. Each combination involves different vegetation types such as grass, shrub and arbor. The proportion and sowing density of each plant species in different combinations are shown in Table 4.

Table 4. Plant combination design and seeding rate for each of species in different combinations

\begin{tabular}{|c|c|c|c|c|c|c|c|c|c|c|c|c|c|c|c|}
\hline $\begin{array}{l}\text { Combi } \\
\text { nation }\end{array}$ & $\begin{array}{l}\text { Amo } \\
\text { rpha }\end{array}$ & $\begin{array}{l}\text { Vit } \\
\text { ex }\end{array}$ & $\begin{array}{c}\text { Euon } \\
\text { ymus } \\
\text { sinen } \\
\text { sis }\end{array}$ & $\begin{array}{l}\text { Tall } \\
\text { fes } \\
\text { cue }\end{array}$ & $\begin{array}{l}\text { Snake } \\
\text { berry }\end{array}$ & $\begin{array}{l}\text { Worm } \\
\text { wood }\end{array}$ & $\begin{array}{c}\text { Alf } \\
\text { alf } \\
a\end{array}$ & $\begin{array}{l}\text { Dian } \\
\text { thus }\end{array}$ & $\begin{array}{l}\text { Cajanu } \\
\text { scajan }\end{array}$ & $\begin{array}{c}\text { Lespe } \\
\text { deza } \\
\text { bicol } \\
\text { or }\end{array}$ & $\begin{array}{c}\text { Crota } \\
\text { laria } \\
\text { palli } \\
\text { da }\end{array}$ & $\begin{array}{c}\text { Leuc } \\
\text { aena } \\
\text { glau } \\
\text { ca }\end{array}$ & $\begin{array}{c}\text { Mi } \\
\text { mos } \\
\text { a } \\
\text { sepi } \\
\text { aria }\end{array}$ & $\begin{array}{c}\text { Dodo } \\
\text { naea } \\
\text { visco } \\
\text { sa }\end{array}$ & $\begin{array}{c}\text { Acaci } \\
\text { a } \\
\text { farne } \\
\text { siana }\end{array}$ \\
\hline $\mathrm{C} 1$ & 20 & 50 & 10 & & & & & 8 & & & & 6 & 8 & & \\
\hline C2 & 10 & & & 20 & 20 & & 8 & & & 8 & 10 & & & & \\
\hline $\mathrm{C} 3$ & 20 & & 50 & & & 20 & & & 10 & & & 8 & & 10 & \\
\hline $\mathrm{C} 4$ & & 30 & & & 20 & & & & & 20 & & & 8 & & 10 \\
\hline C5 & & 20 & & 30 & & 50 & & 10 & & 8 & & 8 & & & \\
\hline C6 & 30 & & 20 & & 50 & & 10 & & 20 & & 8 & & 10 & & \\
\hline $\mathrm{C} 7$ & 10 & 20 & & 30 & & 20 & & 10 & & 20 & & 10 & & & 8 \\
\hline $\mathrm{C} 8$ & & & 30 & & 10 & & 20 & & 30 & & 10 & & 20 & & \\
\hline $\mathrm{C9}$ & 30 & & 20 & & 20 & & & 10 & & 20 & & 8 & & & 10 \\
\hline $\mathrm{C} 10$ & 20 & & & 10 & & 30 & & & 10 & & 10 & & 8 & & 6 \\
\hline $\begin{array}{l}\text { Germi } \\
\text { nation } \\
\text { rate/\% }\end{array}$ & 90 & 70 & 80 & 50 & 75 & 50 & 26 & 35 & 35 & 45 & 50 & 40 & 50 & 35 & 55 \\
\hline
\end{tabular}

\subsection{Experimental indicators}

In this study, the survival rate (\%), plant height $(\mathrm{cm})$, coverage (\%) and aboveground and underground biomass (fresh and dry weight; $\mathrm{g} / \mathrm{pot}$ ) were measured. The dynamic observation was carried out for 3 months in a 5-day measuring period. Matrix respiration (Liang et al., 2017) and soil hardness (TE-3, Nanjing) were measured by ACE automatic soil respiration monitoring system ( $A C E, U K)$.

Among them, the formula for calculating the total survival rate is: the total survival rate of herbs $/ \%=$ (the total survival number of herbs / the total germination number of herbs) $\times 100$, and the calculation of shrubs and arbors is the same.

\subsection{Data analysis}

The mathematical statistical method used in this study is one-way ANOVA, which is mainly used to test the significant difference of soil respiration and soil hardness among plant community combinations (LSD test) in order to determine the best plant community combinations. Simple correlation analysis is used to evaluate the two-way correlation among variables (Liu et al., 2017). Excel 2018 and SPSS (version 20.0) software are used for data analysis. The plant names used in this paper are based on those recorded in the Chinese Digital Herbarium (CVH for short, website: www.cvh.org.cn).

\section{Results}

In this study, 15 greening plants commonly used on slopes in southern China were used to design 10 different combinations of plant communities. The initial growth and competition of plant communities in slope ecological restoration were investigated by observing the changes of survival number, coverage, biomass and soil microbial respiration and hardness in different combinations. The experimental results were used to optimize the plant community allocation model in slope ecological restoration.

\subsection{Survival rates of different plant communities}

Survival rate is an intuitive index to evaluate the effect of plant community allocation in slope ecological restoration. In this paper, the survival rate of plants in different combinations of plant communities is designed as shown in Table 5.

The results of Table 5 show that the survival rate of arbors and shrubs is significantly lower than that of herbs. As far as herbs are concerned, the higher the sowing density is, the lower the survival rate will be, and the final survival number will basically be the same. The survival rate of arbors and shrubs is directly affected by the sowing density of herbs (Wu et al., 2017). The survival number of shrubs and arbors varies with the planting density of herbaceous plants when the same planting density is set in each combination. 
The survival rates of herbs, shrubs and arbors of different plant species were obtained from the results of the survival rates of each plant community combination in Table 5, as shown in Table 6 .

Table 5. Average survival number of species in different combinations

\begin{tabular}{|c|c|c|c|c|c|c|c|c|c|c|c|}
\hline Serial number & Plant name & C1 & C2 & C3 & C4 & C5 & C6 & C7 & C8 & C9 & C10 \\
\hline 1 & Amorpha/\% & 30 & 60 & 50 & & & 60 & 40 & & 60 & 50 \\
\hline 2 & Vitex/\% & 70 & & & 40 & 40 & & 50 & & & \\
\hline 3 & Euonymus sinensis/\% & & & 70 & & & 50 & & 60 & 50 & \\
\hline 4 & Tall fescue/\% & & 60 & & & 60 & & 60 & & & 40 \\
\hline 5 & Snakeberry/\% & & 50 & & 50 & & 60 & & 40 & 40 & \\
\hline 6 & Wormwood/\% & & & 40 & & 60 & & 40 & & & 50 \\
\hline 7 & Alfalfa/\% & & 50 & & & & 50 & & 40 & & \\
\hline 8 & Dianthus/\% & 50 & & & & 40 & & 60 & & 60 & \\
\hline 9 & Cajanuscajan/\% & & & 80 & & & 40 & & 80 & & 60 \\
\hline 10 & Lespedeza bicolor/\% & & 50 & & 40 & 50 & & 50 & & 40 & \\
\hline 11 & Crotalaria pallida/\% & & 40 & & & & 50 & & 60 & & 40 \\
\hline 12 & Leucaena glauca/\% & 50 & & 50 & & 50 & & 40 & & 50 & \\
\hline 13 & Mimosa sepiaria/\% & 25 & & & 50 & & 40 & & 40 & & 50 \\
\hline 14 & Dodonaea viscosa/\% & & & 40 & & & & & & & \\
\hline 15 & Acacia farnesiana/\% & & & & 60 & & & 50 & & 60 & 50 \\
\hline
\end{tabular}

Table 6. Survival rate of plant species in different combinations

\begin{tabular}{cccc}
\hline Plant community & Herbal total survival rate/\% & Shrub total survival rate/\% & Arborwood survival rate/\% \\
\hline C1 & 22.1 & 12.5 & 26.5 \\
\hline C2 & 22.2 & 14.3 & 24.5 \\
\hline C4 & 55.6 & 14.5 & 13.3 \\
\hline C5 & 53.5 & 12.8 & 13.3 \\
\hline C6 & 18.3 & 12.5 & 19.4 \\
\hline C7 & 36.7 & 10.9 & 11.8 \\
\hline C8 & 40.8 & 17.9 & 19.4 \\
\hline C9 & 19.1 & 14.3 & 30.5 \\
\hline C10 & 25.6 & 17.4 & 19.0 \\
\hline
\end{tabular}

Table 7. Ratio of population density between vegetation types in plant community combinations

\begin{tabular}{cccc}
\hline Plant community & Herb/shrub/\% & Herb/arbor/\% & Shrub/arbor/\% \\
\hline C1 & 17.71 & 4.72 & 0.38 \\
\hline C2 & 8.86 & 2.58 & 0.29 \\
\hline C3 & 8.86 & 8.29 & 0.93 \\
\hline C4 & 5.28 & 4.05 & 0.79 \\
\hline C5 & 11.00 & 4.06 & 0.37 \\
\hline C6 & 7.69 & 7.01 & 0.91 \\
\hline C7 & 21.05 & 4.43 & 0.21 \\
\hline C8 & 19.10 & 14.30 & 30.5 \\
\hline C9 & 14.12 & 21.31 & 1.51 \\
\hline C10 & 13.66 & 6.41 & 0.47 \\
\hline
\end{tabular}

Combining the results of visual data analysis in Table 5 and Table 6, we can see that the dominant combinations of total survival of herbs are $\mathrm{C} 3, \mathrm{C} 4$ and $\mathrm{C} 7$; the highest combinations of shrub survival are $\mathrm{C} 7, \mathrm{C} 9$ and $\mathrm{C} 3$, and the highest combinations of total survival of arbors are $\mathrm{C} 8, \mathrm{C} 10$ and $\mathrm{C} 1$. On the whole, the survival rate of herbs was higher than that of shrubs.

Based on the above results, the population density among different vegetation types in different plant community combinations can be obtained as shown in Table 7.

Studying the effects of sowing density and plant proportion on community coverage plays an important role, which can directly reflect the quantitative characteristics and diversity trends of community. The results of Table 7 show that $\mathrm{C} 7$ and $\mathrm{C} 8$ are the most diverse plant community combinations in the above plant community combinations. 3.2. Dynamic changes of plant coverage in different plant communities

During the experiment, the dynamic changes of plant coverage of different plant community combinations in slope ecological restoration are shown in Table 8.

In the three-month growth cycle set in this study, the overall growth rate of herbaceous plant coverage was much faster than that of shrubs and arbors, and herbaceous plants became the dominant species in the early stage after mixed sowing. The growth trend of 
herbaceous plant coverage with time was not related to sowing density. There is a great difference between the ratio of grass to shrub and the ratio of grass to arbor (Gao et al., 2017). Therefore, it is preliminarily concluded that in the initial stage of slope spraying, the growth of herbage is less affected by shrubs and arbors. Unlike herbaceous plants, the ratio of herbaceous shrub density has a greater impact on the coverage of some shrubs. Arbor growth is also affected by the ratio of grass to arbor, that is, the larger the ratio, the slower the coverage growth. This result shows that in the future slope ecological restoration, the proportion of herbaceous plants planted should not be too large than shrubs and arbors, otherwise, it will seriously affect the initial growth of shrubs and arbors, especially for the strong creeping herbaceous plants. Besides the ratio of grass to shrub and the ratio of grass to arbor are the main factors affecting the initial growth of arbors and shrubs, and the seeding density of herbaceous plants is also one of the key factors. In a word, choosing the appropriate proportion of grass seeds and reasonable planting density can not only save costs, but also ensure the normal growth of shrubs and arbors at the initial stage. Although herbaceous plants usually occupy the dominant position in the early stage of community growth, considering that their long-term competitiveness is lower than shrubs and arbors, and may even be gradually eliminated in community succession, higher selection can be made in the selection process of plant community combinations to ensure the normal growth of shrubs and arbors (Nadia and Emad, 2020; Ogulmus et al., 2016). Table 8 shows that the coverage of $\mathrm{C} 7$ combination reaches $100 \%$ first on the 40 th day, followed by the coverage speed of $\mathrm{C} 1$, which is $50 \mathrm{~d}$. C3 did not reach $100 \%$ until the eightieth day. Considering various factors, C3 and C5 are the combination of slower growth rate, $\mathrm{C} 7$ and $\mathrm{C} 1$ plant community combination has better coverage effect.

Table 8. Dynamic changes of plant coverage in different combinations

\begin{tabular}{ccccccccccc}
\hline Number of days & $\mathbf{C 1 / \%}$ & $\mathbf{C 2 / \%}$ & $\mathbf{C 3 / \%}$ & $\mathbf{C 4 / \%}$ & $\mathbf{C 5} / \%$ & $\mathbf{C 6 / \%}$ & $\mathbf{C 7 / \%}$ & $\mathbf{C 8} / \%$ & $\mathbf{C 9 / \%}$ & $\mathbf{C 1 0} / \%$ \\
\hline 5 & 5.68 & 6.15 & 5.48 & 7.25 & 5.16 & 6.23 & 7.18 & 5.24 & 5.81 & 6.64 \\
\hline 10 & 11.25 & 12.63 & 10.25 & 12.36 & 11.35 & 13.62 & 15.024 & 11.05 & 10.45 & 12.62 \\
\hline 15 & 22.61 & 24.61 & 22.15 & 25.61 & 22.34 & 27.64 & 33.51 & 22.16 & 23.51 & 24.61 \\
\hline 20 & 41.62 & 38.16 & 37.62 & 43.51 & 41.65 & 48.62 & 51.13 & 42.65 & 46.58 & 43.25 \\
\hline 25 & 68.49 & 65.18 & 61.52 & 70.25 & 63.54 & 71.52 & 72.61 & 58.16 & 47.85 & 58.61 \\
\hline 30 & 78.36 & 71.52 & 68.16 & 77.62 & 71.62 & 78.61 & 83.16 & 65.61 & 58.25 & 63.48 \\
\hline 35 & 84.16 & 80.25 & 70.15 & 81.62 & 76.52 & 82.61 & 92.46 & 72.65 & 61.54 & 66.82 \\
\hline 40 & 95.16 & 86.61 & 75.61 & 84.36 & 79.64 & 87.62 & 100 & 78.61 & 65.12 & 71.56 \\
\hline 45 & 97.53 & 91.52 & 78.62 & 87.61 & 82.61 & 90.45 & 100 & 86.12 & 72.34 & 78.61 \\
\hline 50 & 100 & 93.54 & 81.26 & 90.25 & 84.62 & 93.51 & 100 & 91.52 & 79.158 & 86.52 \\
\hline 55 & 100 & 95.48 & 84.62 & 93.52 & 87.62 & 98.61 & 100 & 94.85 & 86.13 & 91.52 \\
\hline 60 & 100 & 98.61 & 86.21 & 96.48 & 89.61 & 100 & 100 & 97.52 & 91.58 & 97.52 \\
\hline 65 & 100 & 100 & 89.64 & 100 & 93.52 & 100 & 100 & 100 & 96.48 & 100 \\
\hline 70 & 100 & 100 & 91.52 & 100 & 96.84 & 100 & 100 & 100 & 100 & 100 \\
\hline 75 & 100 & 100 & 93.25 & 100 & 100 & 100 & 100 & 100 & 100 & 100 \\
\hline 80 & 100 & 100 & 95.64 & 100 & 100 & 100 & 100 & 100 & 100 & 100 \\
\hline 85 & 100 & 100 & 100 & 100 & 100 & 100 & 100 & 100 & 100 & 100 \\
\hline 90 & 100 & 100 & 100 & 100 & 100 & 100 & 100 & 100 & 100 & 100 \\
\hline & & & & & & & & &
\end{tabular}

\subsection{Biomass and soil characteristics of different plant community combinations}

The results of biomass and soil properties of different plant community combinations are shown in Table 9.

According to the results of Table 9, it can be seen that although the coverage of $\mathrm{C7}$ reaches $100 \%$ quickly, its initial growth is not high. Its aboveground biomass is $321.98 \pm$ $25.18 \mathrm{~g}$, which is significantly lower than C8. The corresponding basic soil respiration is only $8.06 \pm 2.03 \mathrm{~mol}$ $\mathrm{CO}_{2} /\left(\mathrm{m}^{2} \cdot \mathrm{s}\right)$, which is significantly lower than that of $\mathrm{C} 3$ with relatively slow coverage rate. $\mathrm{C} 5$. That is to say, too fast herbage mulching speed reduces soil respiration. Soil hardness decreases with the increase of species diversity and underground biomass (Uzun and Donmez, 2016). It is preliminarily deduced that in the early stage of engineering construction, the dominance of plant species with slower growth at the root stage can effectively improve soil hardness and increase the ability of soil to resist rain erosion and wind erosion. There was no significant correlation between total biomass and species diversity ( $p$ $>0.05$ ).

In the process of slope ecological restoration, plant community allocation should control the spraying proportion of each plant, and select dominant plants which grow slowly at the initial stage of root of herbaceous plants, which is beneficial to the development of target plant types of grass, shrub and arbor in a stable and reasonable spatial and temporal distribution pattern, and effectively improve the anti-scouring ability of slope. According to the characteristics of soil, through sorting, the results are as follows: C7: 10 plants of Amorpha fruticosa+20 plants of Vitex negundo+30 plants of Festuca arundinacea+20 plants of Moxa argyi+10 plants of Dianthus caryophylla+20 plants of Lespedeza+10 plants of Leucaena+8 plants of Acacia; C8: 30 plants of Euonymus microphylla+10 plants of Shearnut +20 plantsof Alfalfa +30 plants of Pigeon beans +20 plants of Crotalaria mucronata+20plants of Mimosa bimucronata; C3: 20 plants of Amorpha fruticosa+50 plants 
of Euonymus fortunei var. radicans +20 plants of Aicao +10 plants of Pigeon bean +8 plants of Leucaena +10 plants of
Dodonaea viscosa are the optimal plant communities for ecological restoration.

Table 9. Biomass and soil properties of different combinations of plant communities

\begin{tabular}{|c|c|c|c|c|c|c|}
\hline $\begin{array}{c}\text { Combinatio } \\
n\end{array}$ & $\begin{array}{c}\text { Number of } \\
\text { species/n }\end{array}$ & $\begin{array}{l}\text { The total number } \\
\text { of days required } \\
\text { to cover } 100 \% / d\end{array}$ & $\begin{array}{l}\text { Aboveground total } \\
\text { biomass/gDW }\end{array}$ & $\begin{array}{l}\text { Total underground } \\
\text { biomass/gDW }\end{array}$ & $\begin{array}{c}\text { Soil based } \\
\text { breathing/mol } \\
\mathrm{CO}_{2} /\left(\mathrm{m}^{2} \cdot \mathrm{s}\right)\end{array}$ & $\begin{array}{c}\text { Soil } \\
\text { hardness } / \mathrm{kg} / \mathrm{c} \\
\mathrm{m}^{2} \\
\end{array}$ \\
\hline $\mathrm{C} 1$ & 6 & 50 & $209.52 \pm 28.26$ & $57.46 \pm 3.96$ & $6.61 \pm 0.78$ & $0.14 \pm 0.01$ \\
\hline $\mathrm{C} 2$ & 6 & 65 & $283.21 \pm 34.19$ & $42.58 \pm 1.52$ & $6.67 \pm 1.22$ & $0.19 \pm 0.09$ \\
\hline $\mathrm{C3}$ & 6 & 85 & $260.38 \pm 25.19$ & $51.29 \pm 2.14$ & $9.13 \pm 0.82$ & $0.18 \pm 0.01$ \\
\hline C4 & 5 & 65 & $215.51 \pm 29.92$ & $72.24 \pm 5.42$ & $10.12 \pm 0.25$ & $0.16 \pm 0.02$ \\
\hline $\mathrm{C} 5$ & 6 & 75 & $265.70 \pm 17.75$ & $86.98 \pm 11.76$ & $11.53 \pm 0.47$ & $0.19 \pm 0.05$ \\
\hline C6 & 7 & 60 & $200.68 \pm 16.55$ & $71.14 \pm 4.92$ & $7.05 \pm 1.22$ & $0.17 \pm 0.06$ \\
\hline $\mathrm{C7}$ & 8 & 40 & $321.98 \pm 25.18$ & $85.31 \pm 2.99$ & $8.06 \pm 2.03$ & $0.14 \pm 0.03$ \\
\hline $\mathrm{C} 8$ & 6 & 65 & $472.18 \pm 53.21$ & $86.63 \pm 1.15$ & $17.07 \pm 2.67$ & $0.15 \pm 0.05$ \\
\hline $\mathrm{C9}$ & 7 & 70 & $263.90 \pm 34.43$ & $46.49 \pm 3.52$ & $7.52 \pm 1.05$ & $0.22 \pm 0.04$ \\
\hline C10 & 7 & 65 & $240.62 \pm 36.88$ & $57.16 \pm 3.31$ & $6.41 \pm 0.84$ & $0.20 \pm 0.06$ \\
\hline
\end{tabular}

3.4. Example of optimal allocation model of plant community in slope ecological restoration

Based on the experimental results, the optimal allocation of plant communities in slope ecological restoration was applied to Xinnan Expressway by using the 3D Max simulation software. The results are as follows:

The C7 combination is applied to the diamond skeleton slope optimization sketch as shown in Figure 1.

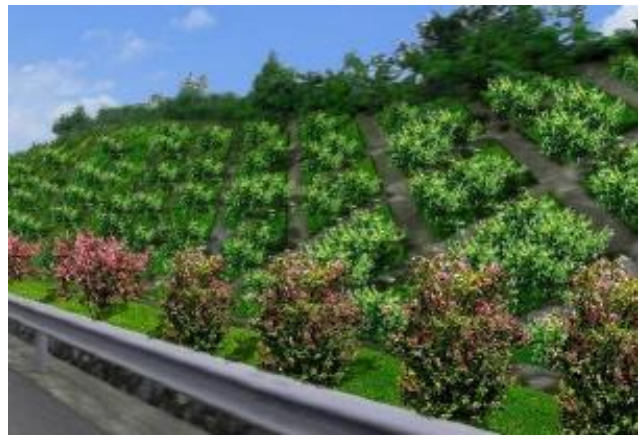

Figure 1. Schematic diagram of applying the $\mathrm{C} 7$ combination to the slope of the diamond skeleton

The C3 combination is applied to the optimization sketch of the upper slope as shown in Figure 2.

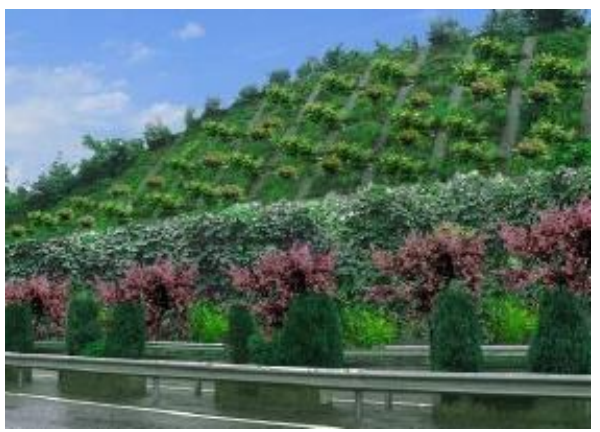

Figure 2. Schematic diagram of applying $\mathrm{C} 3$ combination to higher upper slope optimization

The $\mathrm{C} 8$ combination is applied to the optimization sketch of slope under herringbone skeleton as shown in Figure 3.
Through the above three effect maps, it can be seen that the optimized plant community is deployed in the slope of expressway, with a wide coverage and neat and beautiful, which verifies the effectiveness of the optimized allocation results in this paper.

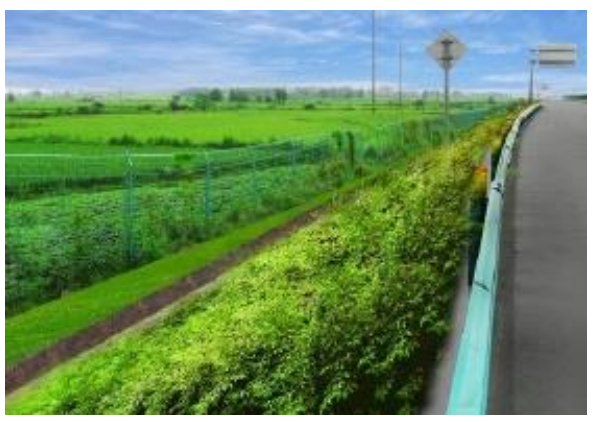

Figure 3. Schematic diagram of applying C8 combination to the slope under the herringbone skeleton

\section{Discussions}

The general principle of plant community type design in slope ecological restoration is to establish a plant community that conforms to local site conditions and is in harmony with the surrounding environment. According to the principles of restoration ecology and the design and construction methods of ecological engineering, the following principles should be met in designing reasonable plant community types on slopes:

(1) Principle of nature

The types of plant communities for slope ecological restoration should conform to the local natural environment and try to coordinate the restoration vegetation with the original vegetation. Therefore, it is necessary to make a detailed investigation of the local vegetation and climate before determining the type of plant community, so as to determine the species suitable for the local site conditions according to the local actual situation, and make a reasonable combination.

\section{(2) Safety principles}

Plant community type design should be combined with slope type, and the selected species will not pose a threat to slope stability and surrounding environment. Local 
species should be selected as far as possible in species selection, so as to avoid introducing a large number of alien species, especially invasive plant species, in order to avoid causing a large number of species invasions in the future.

\section{(3) Principle of diversity}

Stable plant communities are mostly composed of arbors, shrubs, grasses and other species. It is difficult for a single species to form a stable plant community. Therefore, in the design of plant community types, attention should be paid to the rational combination of arbor, shrub, grass and other species in the vertical structure (Grubisic-Cabo et al., 2018), horizontal structure and time structure, so as to change the current situation of single use of herbaceous plants in slope ecological restoration, and build a plant community with rich and stable species.

(4) Functional principles

The purpose of slope ecological restoration is to restore the original plant types by engineering means, so as to achieve the goal of slope stability and soil erosion control. According to the characteristics of slopes, the functions and characteristics of plants should be considered in the design of plant community types, plant types with soil and water conservation effect, slope stabilization ability and drought tolerance should be selected as far as possible.

\section{(5) Landscape principles}

In addition to the above principles, the landscape effect of plants should be considered in the design of plant community types. On the basis of meeting the functional requirements of slope protection, the species with high landscape value should be selected as far as possible to form a landscape effect in harmony with the surrounding environment.

Based on the design principles of plant communities on slopes, the design methods of plant communities on several typical engineering slopes are as follows:

\section{(1) Design of plant community types on highway (railway) slope}

Although a variety of concession measures have been taken in the process of highway (railway) construction, it is inevitable that a large number of bare slopes have been formed and the local natural environment has been destroyed. Therefore, we must rely on artificial methods to restore plant communities and prevent soil erosion. The plant community type of highway (railway) slope should be determined according to its location.

\section{a. Design of plant community types on highway (railway) slopes in suburbs of cities}

The slope or highway entrance near the urban area requires a higher landscape. Therefore, the plant community type should be coordinated with the surrounding environment, with shrubs and flowers with high ornamental value as the main part, and special plant communities should be established. In species selection, attention should be paid to the rational combination of color and shape to form a plant community which is in harmony with the surrounding environment and can reflect its own characteristics.

b. Design of plant community types on highway (railway) slopes in Mountainous Areas

It is advisable to establish shrub-grass plant communities on the slopes far away from urban areas and avoid planting arbors. Because of the heavy weight of arbors themselves, planting arbors will lead to the instability of the slope, and affect the vision of the crew, improve the probability of traffic accidents. In species selection, some species with developed roots, good soil and water conservation effect, drought tolerance and barren tolerance should be the first choice, and their vertical structure should be rationally matched to form a community with high species richness and rich changes in landscape.

\section{(2) Design of plant community types in mine wasteland}

According to the geomorphological characteristics of different areas of mine wasteland and the degree of difficulty in harnessing, the plant community can adopt the design mode of climbing rattan with hanging feet on the top of slope, spraying and embellishing in the middle, planting arbors on the site, and returning to nature in harmony as a whole, so as to realize the rational allocation of plant space-time according to local conditions and enhance the function of ecosystem.

\section{a. Type design of plant communities in traces}

The slope of the traced land is usually gentle, much easier to construct than that of the stone wall, and the plants are easier to take root, so the ecological restoration is also easier. At present, there are several main forms of ecosystem reconstruction of the target land in the world, namely, reconstruction for cultivated land, reconstruction for woodland, reconstruction for tourism and leisure land, reconstruction for pastoral land and so on. In the design of plant community types for ecological restoration of trackland, appropriate reconstruction forms should be selected according to the surrounding environment of trackland, and then plant community types should be designed. Because most areas of the traces are waste slag, which is not conducive to plant growth, it is necessary to cover a layer of soil on the surface of the ecological restoration, and select some nitrogen-fixing plants with the ability to improve the soil when selecting species. If we want to rebuild the forest land, we should take the arborshrub plant community as the target plant community. In the process of ecological restoration, we can select some fast-growing herbaceous plants with soil improvement as pioneer species to control soil erosion and improve soil quality. Then we can select some local arbors and shrubs to gradually restore to arbors. If it is rebuilt as a park, some species such as arbors, shrubs, flowers and grasses with good landscape effect should be chosen as the preferred species in the design of plant community types. Combining with the surrounding environment, some special shapes should be designed to form an ecological park which can integrate with the surrounding environment and has high species richness and ornamental value. In order to restore the land for animal husbandry, herbaceous plant 
communities should be taken as the target plant communities, and herbaceous plant species should be selected. Some grass species with strong vitality, rapid growth, trampling tolerance and extensive management are preferred.

\section{b. Design of stone wall plant community types}

Because the stone wall is very steep, the surface is very smooth, and the temperature difference is large, there is no soil or loose matrix; it is very difficult to keep water and fertilizer on the slope, which determines that the ecological restoration of the mine wasteland is the key to ecological restoration. Therefore, in the design of plant community types, whether the plant selection is reasonable or not plays a vital role in the success of ecological restoration. The ecological restoration of stone wall should be based on the lithology, slope, surface roughness and other characteristics of species selection. Herb-type plant communities should be established in rock-wall plant communities of abandoned mines, and some vines and shrubs should be planted at small platforms and holes to embellish them.

c. Design of plant community types at the top and foot of slope

On the top of excavated slopes, planting troughs are built and backfilled with planting soil. Vertical vines and shrubs are planted in planting troughs. Point green belts are formed on the top of hills. The sagging vines can also cover part of bare rock mass. The function of soil and water conservation is powerful, and the visual effect of landscape is vivid. Similarly, in the planting trough at the foot of the slope, climbing and flowering species such as Prunustrifoliata, Phalaenopsiscrassipes and Mucunasempervirens Hemslwere planted to form a harmonious plant community.

(3) Design of plant community types on waterfront and slope

Waterfront slope is the link between water and land, and the last barrier for ground pollutants to enter the water body. Healthy slope vegetation can effectively control nonpoint source pollution, reduce the content of pollutants in runoff, intercept organic matter in runoff, absorb and utilize various nutrients discharged naturally or artificially, so as to improve river water quality and avoid large-scale reproduction of phytoplankton and algae. The special function requirement of riparian vegetation determines that in the design of plant community types on riparian slope, besides the function of vegetation revetment and beautifying the environment, the reduction of pollutants in water should also be considered.

\section{a. Design of plant community types on water slopes}

The main function of plant communities on water slopes is to protect slopes and intercept pollutants from entering rivers. Therefore, shrub-grass type should be the target of plant community types. In species selection, shrubs and herbaceous plants with well-developed roots and the function of adsorbing and degrading pollutants should be selected, and combined with the surrounding environment, with flowers and plants appropriately, to build a plant.

\section{b. Design of plant community types on underwater slope}

Underwater slopes are immersed in water all the year round, and the light flux is not good. Therefore, in the design of plant community types, submerged plants with waterlogging resistance, well-developed roots and reducing pollutants in water, such as Potamogetonmalayi, goldfish algae, hydrilla, etc., should be mainly used to form a reservoir bank purification zone while reveting and fixing slopes, so as to convey surface runoff into rivers. It can prevent, absorb and transform the organic matter and nutrients that may enter the water body. It is beneficial to the self-purification of the water body, prevent eutrophication of the water body, reduce the light flux into the water body, inhibit the growth of planktonic algae and increase the transparency of the water.

\section{Conclusions}

In order to effectively optimize the allocation pattern of plant communities in slope ecological restoration, 10 plant community combinations were designed by selecting 15 plants. The optimal three combinations were selected through the survival rate, coverage and soil hardness of each plant in the plant community combinations, which were used as plant communities in the process of slope ecological restoration of Xinnan Expressway. Because of the different geographical location and soil conditions in different areas, the results of this study can only be used as the optimization results of plant community allocation in slope ecological restoration of Xinnan Expressway. The selection and application of native plants is the key to the success or failure of slope greening. In addition to the common native plants of tall fescue, Acacia fruticosa, wattle and Alfalfa on the slope of expressway, the more adaptable plants such as bermudagrass, Duchesnea indica, vetch and argyrophyte should also be selected to select the best pattern of slope vegetation allocation. Landscape and ecology can meet the needs of slope greening and protection on the largest scale. There are abundant native plant resources on the slope of Xinnan Expressway, but it is a long-term process to use native plant to restore and construct the slope greening, which needs continuous exploration and experiment. Therefore, the following points should be paid attention to in this process: unified planning and cooperation in the early stage, paying attention to the protection of wild plant gene pool, etc. Reduce the damage of highway construction to the habitat and vegetation of wild plant communities; promote the construction of local nurseries; at the same time, strengthen the guidance and support of the government; improve the market system and regulations.

\section{Acknowledgement}

The Social Science Start-up Project Fund of Shenzhen University (University level): Urban Greenway and Street Landscape Integration Based on Urban Planning (No. 16QFC54); Teaching and Research Project Fund of Shenzhen University in 2018 
(University level): Teaching Model of Chinese Garden History Based on VR Experience (No. JG2018037).

\section{References}

Aja D., Elias E. and Obiahu O.H. (2020), Flood risk zone mapping using rational model in a highly weathered Nitisols of Abakaliki Local Government Area, South-eastern Nigeria, Geology, Ecology, and Landscapes, 4, 131-139.

Emanuel J.L. and Uffe J. (2020), The mineral nitrogen distribution from the combined free-range pig farming and energy crop production system, Malaysian Journal of Sustainable Agriculture, 4, 75-80.

Gao W., Kanna M.R.R., Suresh E. and Farahani M.R. (2017), Calculating of degree-based topological indices of nanostructures, Geology, Ecology, and Landscapes, 1, 173183.

Grubisic-Cabo F., Nizetic S., Coko D., Kragic I.M. and Papadopoulos A. (2018), Experimental investigation of the passive cooled free-standing photovoltaic panel with fixed aluminum fins on the backside surface, Journal of Cleaner Production, 176, 119129.

Guo J.G. and Huang S. (2017), Study on architecture of big data based on military intelligence analysis and service system, Journal of China Academy of Electronics and Information Technology, 12, 389-393.

Haapalehto T., Juutinen R. and Kareksela S. (2017), Recovery of plant communities after ecological restoration of forestrydrained peatlands, Ecology \& Evolution, 7, 7848-7858.

Liang L.I., Zhang J.J., Chen B.Q. (2017), Changes of vegetation community characteristics in closed small watershed of the loess plateau in Western Shanxi Province, Northern China, Journal of Beijing Forestry University, 39, 78-89.

Linag Z., Wu Z. and Noori M. (2017), A new ecological control method for Pisha sandstone based on hydrophilic polyurethane, Journal of Arid Land, 9, 790-796.

Lindh B.C. (2018), Tipping the native-exotic balance: succession in restored upland prairies in Oregon's Willamette Valley, Ecological Restoration, 36, 28-40.

Liu H.J., Chen A.S. and Zhen H. (2017), Research on operation and management mode of intelligent substation based on regulating and controlling, Chinese Journal of Power Sources, 41, 1374-1376.

Liu Y., Zhang L.J. and Han Y.N. (2018), Financial credit risk evaluation model of supply chain finance based on particle swarm cooperative optimization algorithm, Journal of Jilin University (Science Edition), 56, 119-125.

Liu Z.B., Wang Y.H. and Yu L. (2017), Spatiotemporal variation and scale effect of canopy leaf area index of larch plantation on a slope of the semi-humid Liupan Mountains Ningxia, China, Chinese Journal of Plant Ecology, 41, 749-760.

Muller I., Delisle M. and Ollitrault M. (2017), Responses of riparian plant communities and water quality after 8years of passive ecological restoration using a $\mathrm{BACl}$ design, Hydrobiologia, 781, 1-13.

Nadia M.E.S. and Emad A.S. (2020), Wild medics from different original habitats can be used as forage legumes in salt affected soil, Journal Clean Was, 4, 32-40.

Niu Y.J., Zhou J.W. and Yang S.W. (2017), Quantitative apportionment of slope aspect and altitude to soil moisture and temperature and plant distribution on alpine meadow, Chinese Journal of Applied Ecology, 28(5), 1489.

Ogulmus R., Tasdemir Y. and Cindoruk S.S. (2016), Polychlorinated Biphenyl (PCB) levels in soils near wastewater treatment plants and landfills, EKOLOJI, 25, 1-8.

Olusola F.O. (2020). Groundwater quality evaluation for drinking, domestic and irrigation uses in parts of ode irele local Government area of Ondo State, Nigeria, Water Conservation and Management, 4, 32-41.

Peng H., Zeng R. and Du P. (2017), Reliability analysis of typical wiring of urban high voltage distribution network considering self-investment configuration strategy, Automation \& Instrumentation, 189-193.

Pipas K. and Varun J. (2019), Modelling surface run-off response using hydrological model swat in the upper watershed of river Subarnarekha, India, Earth Sciences Malaysia, 3, 9-15, DOI: 10.26480/esmy.02.2019.09.15

Poudel M., Adhikari P. and Thapa K. (2019). Biology and control methods of the alien invasive weed Mikania Micrantha: A review, Environmental Contaminants Reviews, 2, 6-12.

Qolipour M., Mostafaeipour A., Saidi-Mehrabad M. and Arabnia H.R. (2019), Prediction of wind speed using a new Greyextreme learning machine hybrid algorithm: A case study, Energy \& Environment, 30, 44-62.

Rahman K.M., Harder M.K. and Woodard R. (2018), Energy yield potentials from the anaerobic digestion of common animal manure in Bangladesh, Energy \& Environment, 29, 13381353.

Rapai S.B., Mcmullin R.T. and Maloles J.R. (2018), An ecological restoration approach to biological inventories: A case study in the collection of a vegetation biolayer that will inform restoration planning, Ecological Restoration, 36, 116-126.

Shen J.C., Zhang Z.H. and Liu R. (2019), Ecological restoration of eroded karst utilizing pioneer moss and vascular plant species with selection based on vegetation diversity and underlying soil chemistry, International Journal of Phytoremediation, 20, $1-11$.

Tian J., Ji J. and Zhong Q. (2017), Analysis on improvement of slope stability in root-soil composite of Piceacrassifolia forest in Helan Mountain, Transactions of the Chinese Society of Agricultural Engineering, 33, 144-152.

Ullah S., Umer S. and Adnan M. (2019). Study of fenced conservation compared to land exposed to grazing in Dera Ghazi Khan (Pakistan), Earth Sciences Pakistan, 2, 5-8.

Uses in parts of Ode Irele local government area of Ondo state, Nigeria, Water Conservation and Management, 4, 32-41.

Uzun F. and Donmez H.B. (2016), Ecotype traits of the natural populations of the birdsfoot trefoil (lotus corniculatus) in association with the geographical parameters of the sampling sites, EKOLOJI, 25, 33-40.

Vimalraj P.G., Parag M.D. and Uniyal A. (2019), Developmental human interface due to train collision of Asian elephant (Elephas Maximus) in Western circle forest division, Uttarakhand, India, Environment \& Ecosystem Science, 3, 1719.

Wang H., An X. and Zhang Z. (2018a), Effect of advanced treatment on ammonia nitrogen contained in secondary effluent from wastewater treatment plant, Fresenius Environmental Bulletin, 27, 2043-2050. 
Wang H., Zhong H. and Bo G. (2018b), Existing forms and changes of nitrogen inside of horizontal subsurface constructed wetlands, Environmental Science and Pollution Research, 25, 771-781.

Wei X., Deng X. and Xiang W. (2017), Calcium content and high calcium adaptation of plants in karst areas of southwestern Hunan, China, Biogeosciences Discussions, 15, 1-29.

Wood J.K., Gold W.G. and Fridley J.L. (2017), An analysis of factors driving success in ecological restoration projects by a university-community partnership, Ecological Restoration, 35, 60-69.

Wu H., Zhao B. and Gao W. (2017), Distance indices calculating for two classes of dendrimer, Geology, Ecology, and Landscapes, 1, 133-142.

Wu X., Wang S. and Fu B. (2018), Land use optimization based on ecosystem service assessment: A case study in the Yanhe watershed, Land Use Policy, 72, 303-312.

Xuan S.X. and Gao Q. (2017), Novel integrated battery charger based on a four-switch inverter for electric vehicles, Journal of Power Supply, 15, 69-74.

Xue Y., Zhang W.Y. and Shen D.D. (2017), Growth factor and model analysis for creative talents of science and technology based on hierarchical clustering, Computer Simulation, 34, 351-355.

Yoshitaka K., Hiroaki K. and Zhu B. (2018), Effects of slope gradient on runoff from bare-fallow purple soil in China under natural rainfall conditions, Journal of Mountain Science, 15, 738-751. 